\title{
Республика Корея в Африке: "Мягкая сила" как базовый инструмент политики
}

В современном мире, находящемся в активной стадии глобализации, получившие независимость, недавно окрепшие державы выходят на международную арену и стремятся укрепить свою позицию, занять новые рынки и получить доступ к ресурсам. Для достижения этих целей им необходимо определить основные инструменты воздействия и взаимодействия с другими странами. Классические инструменты внешней политики, такие как война, экспансия и угроза применения силы в настоящее время не уходят совсем, но теряют свою главенствующую роль. Теперь на смену "жёсткой силе" приходит "мягкая сила", которая подразумевает более лояльные способы достижения желаемых результатов как в рамках внешней политики, так и внутренней.

Первым термин "мягкая сила" ввёл Джосеф Най в начале 1990-х гг., применив его в своём научном труде: "Призвание к лидерству: меняющаяся природа Американской мощи" [6, с. 128]. В соответствии с его определением "мягкая сила" представляет собой форму внешнеполитической стратегии, предполагающей способность добиваться желаемых результатов на основе добровольного участия, симпатии и привлекательности, в отличие от "жёсткой силы", которая подразумевает насильственное принуждение.

Существенное влияние на инструменты "мягкой силы" оказал и научно-технический прогресс. Весомый вклад в возможности государств по распространению своего влияния внесло развитие радио и телевидения, а в конце XX - начале XXI в. - интернета и мобильных сетей. Стала доступна не только информация о той или иной стране и ее привлекательности, но и новые инструменты государственной пропаганды, направленной в том числе и на внешнюю аудиторию [1, с. 133].

Мировая экономика, тесно связанная с геополитикой, увеличивает свои масштабы, существующие рынки трансформируются и производственные центры постоянно перемещаются. После стремительного развития Юго-Восточной Азии, независимая Африка выходит на первый план, как континент с неограниченным потенциалом роста. Африканский континент богат природными ресурсами, также там регистрируется устойчивый демографический рост, который говорит о том, что будет увеличиваться количество потенциальных потребителей, а значит и увеличится спрос на услуги и товары. Вместе с тем среди ряда развитых стран существует тенденция к переносу производства, особенно трудоёмкого, за пределы своего государства, и в этом контексте некоторые из них рассматривают Африку [2]. Несмотря на то, что часть стран продолжает использовать "жёсткую силу", чтобы оказывать влияние и получать доступ к ресурсам в регионе. Большая часть мира, в том числе Республика Корея, предпочитает применять "мягкую силу" для ведения внешней политики и достижения желаемых целей.

\section{Этап становления отношений}

Первые официальные контакты Республики Корея и Африки датируются годами Корейской войны 1950-1953 гг. [3]. Тогда эфооопский пеший батальон участвовал в боевых действиях в составе армии ООН. Корейцы очень высоко оценивают героизм и стойкость африканских солдат, а также их вклад. Недавно в знак признательности в 2019 г. в Аддис-Абеба при поддержке компании Lotte Group был открыт центр помощи ветеранам Корейской войны [3].

\author{
(C) Журавлева Н. С., 2021
}

ЖУРАВЛЕВА Надежда Сергеевна, магистрант кафедры корееведения Дальневосточного фредерального университета (2. Владивосток). E-mail: zhuravleva.ns@list.ru 
Участие батальона в войне оказало большое влияние на будущие отношения Южной Кореи и Эфиопии. Впоследствии Эфиопия стала первой афрриканской страной, в которой была опробована модель передачи собственного опыта Кореи по преодолению отсталости. На протяжении многих лет Эфиопия входит в список главных реципиентов Кореи на Адриканском континенте.

После Корейской войны Республика сама находилась в состоянии не лучше, чем Африканские державы, многие строения были разрушены, электрификация страны оставляла желать лучшего, даже в Сеуле далеко не в каждом районе был свет. Корея находилась в статусе реципиента, получая гуманитарную помощь от международных организаций и, в частности, от США. Её внешняя политика была весьма ограничена, основные силы были сосредоточены на восстановлении страны и преодолении бедности и общей отсталости.

После того, как ООН провозгласила "год Африки", и 17 афрриканских государств получили независимость от европейских держав, Республика Корея предприняла попытку сближения, но в целом дипломатия в Африке заключалась в конкурировании с Северной Кореей. Одна из составляющей этой конкуренции проявлялась в конфронтации голосов на заседаниях ООН. Южная Корея стремилась наладить отношения с Африканскими странами с целью заручиться поддержкой в случае, если возникнет очередной межкорейский конфоликт на фоне затянувшейся холодной войны.

К концу 70-х - началу 80-х гг. Республика Корея значительно увеличила свои экономические возможности и смогла преодолеть проблему бедности и общей отсталости. В этот же период, оставаясь реципиентом, она начинает выступать в роли донора. В 1982 г. президент Чон Духван первым из корейских президентов посещает страны Афррики, а именно: Кению, Сенегал, Габон и Нигерию. В тот же год Республику Корею посещают 9 Африканских лидеров. Правительство направляет специальных послов и делегации доброй воли. Тогда же подписываются различные соглашения, предоставляется безвозмездная помощь, направляются группы сельскохозяйственных исследователей и группы мастеров тхэквондо [3]. Всё это делается из расчёта создать условия для развития практического экономического и технического сотрудничества, путём повышения осведомлённости африканского населения и создания позитивного образа Кореи. Подобные меры, могут быть расценены как ведение внешней политики с применением инструментов "мягкой силы". Эти действия в сторону Африки можно назвать экстренными попытками поиска способов замедления приближения экономического кризиса, нависшего после второго нефтяного шока, посредством создания позитивного фона, который позволил бы получить доступ к рынкам и ресурсам африканских стран, а также поиском союзников или препятствия развитию холодной войны, а после её завершения способ распространить влияние и закрепиться на новых территориях, которые больше не были подвержены гегемонии социализма. Все эти попытки имели весьма условный характер, тогда не существовало соответствующих институтов, которые могли бы регулировать работу в направлении Африки, к тому же правительство не было готово выделять достаточных средств для более активного взаимодействия. По сравнению со странами соседями, такими как Китай или Япония, присутствие Кореи в африканском регионе было незначительным.

\section{Современный этап}

С начала 2000-х гг. африканские страны начинают стремительно меняться, как политически, так и әкономически, они становятся глобальным направлением как континент с неограниченным потенциалом роста. Республика Корея, основной целью которой является стать "Зрелой глобальной страной", приходит к тому, что ей необходимо расширять обмен и наращивать объёмы сотрудничество с Африканским континентом.

Вместе с формированием внешнеполитической стратегии, цель которой определялась в поиске новых рынков и повышении личного статуса на международной арене, начинается современный этап отношений Республики Корея и Афррики. В марте 2006 г. президент Но Мухён посещает ряд африиканских стран, это первые подобные визиты, совершённые после 1982 г. По инициативе Министерства иностранных дел Кореи создаётся Корейско-африканский форум, который впоследствии перейдёт на постоянную основу, станет 
основным консультативным органом для правительства, учёных и граждан и будет играть значимую роль в процессе определения основных направлений взаимодействия и организации совместных проектов. $\mathrm{K}$ августу того же года, вместе с установлением дипломатических отношений с Ганой, Республика Корея устанавливает дипломатические отношения со всеми, на тот момент 53, африканскими странами [3].

На первой встрече Корейско-африканского фрорума была озвучена "Корейская инициатива по развитию Африки". Она определила основные приоритетные направления сотрудничества и до сих пор остаётся главным ориентиром для построения современной стратегии сотрудничества. Эта инициатива состояла из следующих 10 пунктов:

1) К 2008 г. трёхкратно увеличить общую сумму помощи в целях развития Африки.

2) Корея будет стремиться поделиться с африканскими странами личным опытом преодоления бедности и отсталости за короткий промежуток времени.

3) Корея увеличит количество программ по снижению детской смертности, программ по поддержке матери и ребёнка, а также программ по искоренению болезней, включая ВИЧ/СПИД, малярию и туберкулёз.

4) Корея внесёт вклад в развитие человеческого капитала, оказывая поддержку базовому и профессиональному образованию в Африке.

5) Корея расширит свою помощь в сфере сельского хозяйства и рыболовства, чтоб минимизировать проблему дефрицита продуктов питания и содействовать развитию сырьевой промышленности.

6) Распространяя передовые корейские ИКТ в африканских странах, Корея внесёт свой вклад в преодоление цифрового разрыва в регионе.

7) Будет создан Корейско-африканский форум - консультативный орган для правительственных чиновников, учёных и граждан как основной проводник для регулярных консультаций между Кореей и Африкой.

8) Совместно с международными организациями Корея будет работать над улучшением качества и повышением эфрфективности деятельности по развитию Африки.

9) Для улучшения торгового потенциала Африки Корея расширит торговлю и увеличит инвестиции в Африку.

10) Эта инициатива будет осуществляться с акцентом на усилении собственной ответственности Адрикки за своё развитие [12, с. 5-7].

Если проанализировать содержание, то можно заметить, что в основных пунктах "Корейская инициатива развития" повторяет текст Декларации тысячелетия ООН и стратегий сотрудничества с Африкой других стран, таких как Великобритания, Турция. Однако часть пунктов переработана с учётом личного опыта Кореи, а также с расчётом возможности использовать высокий потенциал Кореи в определённых отраслях.

В соответствии с видением администрации Но Мухёна сотрудничество с aфриканским континентом имело по большей части экономический подтекст. В нескольких пунктах инищиативы были уточнения на это указывающие, например, что Корейско-африканский форум в первую очередь должен стать консультативным органом для проектов экономического сотрудничества. Также особо подчёркивалось международное сотрудничество с другими странами в рамках программ по развитию Афррики. Эти уточнения говорят нам о том, что в тот период были предприняты попытки создать благоприятные условия для выхода южнокорейских компаний на рынки Адрики.

В 2007 г. к власти пришёл консерватор Ли Мёнбак, тогда многие решили, что Африка выйдет из поля зрения и станет менее интересна новому правительству. Но очередная встреча Корейско-африканского фрорума в 2009 г. развеяла эти мысли. На встречу были приглашены не только главы афрриканских государств, но и члены Африканского союза, кроме обсуждения результатов прошлого фрорума, Корея обязалась в дальнейшем продолжить сотрудничество с союзом. В 2010 г. Ли Мёнбак в своём новогоднем обращении подчеркнул особый приоритет укрепления дипломатических отношений с африканским континентом, что в свою очередь окончательно избавило от последних сомнений. 
Рис. 1. Общая концепция "Первой региональной стратегии для развития Африки" (2012-2015)

\section{Стратегия по развитию африканского региона}

Видение

\section{Hope WITH Africa}

Долгосрочная

цель

Вклад в гармоничное и постоянное развитие африканского региона
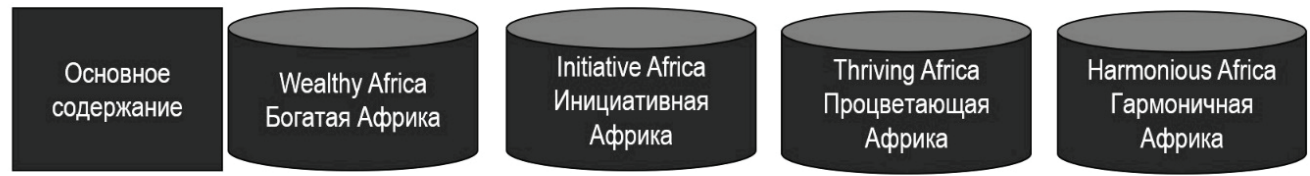

Источник: [9; с. 11].

Во время своего визита в 2011 г. в Демократическую Республику Конго Ли Мёнбак обсудил с Жозефом Кабилой северокорейские испытания баллистических ракет в 2009 г. И чуть позже выразил заинтересованность в расширении коммерческих связей с Конго, что можно расценивать как попытку оказать влияние на Северную Корею через союзные страны. В ответ на экономическую поддержку, в некоторых случаях таможенные преференции или иные послабления союзные страны выражали своё несогласие с политикой КНДР и ограничивали сотрудничество.

В рамках официальных визитов в Африку Ли Мёнбак съездил в Эфиопию. Там он посетил мемориал эфиопским солдатам, сражавшимся в годы Корейской войны. Подчёркивая важность участия Эфиопии в этой войне, он пообещал пригласить потомков эфиопских ветеранов в Корею, чтобы поделиться с ними опытом экономического развития [3]. Так, посетив две страны, которые продолжительное время сотрудничали с Северной Кореей, Ли Мёнбак чётко дал понять, что кроме экономической политики теперь продвигается и геополитика. При нём отношения Африки и Кореи перешли из разряда экономического сотрудничества в международную политику. При этом рычагами давления всё ещё выступала экономическая поддержка и иные гуманитарные проекты сотрудничества.

При Ли Мёнбаке была разработана "Первая региональная стратегия для развития Афррики (2012-2015)", основное видение которой звучало как "Нope WITH Africa" [9, с. 2]. В ней были определены основные четыре идеи (рис 1), которые объединялись в общую цель, заключающуюся в безграничном развитии скрытого потенциала Африки, ведущем Африку к светлому будущему и счастливой жизни каждого. Корея в этом пути должна лишь поддерживать собственные инициативы африканских стран, выступая в роли консультанта и донора. Каждая из четырёх идей объединяла определённые группы проектов. Так "Богатая Африка" включала в себя проекты по развитию отрасли сельского хозяйства и промышленности; "Инициативная Африка" была сосредоточена в области управления, как на правительственном уровне, так и на уровне работы организаций и предприятий; "Процветающая Африка" главным образом опиралась на проекты образования и здравоохранения; "Гармоничная Африка" не определялось какой-то одной сферой, её функции заключалась в гармоничном продвижения проектов, они должны были быть экологичными и равноправными для всех. 
Таблица 1. Оценка эффеективности проектов, выполненных в рамках "Первой региональной стратегии для развития Африки (2012-2015)" в \%.

\begin{tabular}{|l|c|c|c|}
\hline \multicolumn{1}{|c|}{ Область } & Северная Африка & $\begin{array}{c}\text { Центральная } \\
\text { и Западная Африка }\end{array}$ & $\begin{array}{c}\text { Юго-Восточная } \\
\text { Африка }\end{array}$ \\
\hline Правительственные проекты & 0,0 & 0,0 & 40,0 \\
\hline Образование & 100,0 & 90,0 & 90,9 \\
\hline "Зелёная" энергия & 0,0 & 100,0 & 50,0 \\
\hline Сельское хозяйство & 66,7 & 40,0 & 40,0 \\
\hline Здравоохранение & - & 90,9 & 100,0 \\
\hline
\end{tabular}

Составлено на основе: [8, с. 18-22].

Первая стратегия опиралась на "Корейскую инициативу развития Аdррики" и планы поддержки афрриканского континента на 2006-2008 г. и 20082010 г. Кроме этого, были взяты на вооружение Цели развития тысячелетия, представленные на ассамблее $\mathrm{OOH}$ в 2010 г. Для её разработки была собрана "Task Force Team", группа афрриканских представителей, сотрудников центров исследований и отраслевых специалистов. Она просуществовала на протяжении 6 месяцев. Из основных отличий от предыдущих планов развития, которые использовала Корея в своей политике, можно выделить следующие:

- Изменилась политика выбора проектов развития и поддержки. Теперь проекты, которые были предложены корейской стороной и были выгодны по большей части ей же, перестали быть приоритетными. В первую очередь рассматривались проекты развития и поддержки, которые были инициированы африканской стороной и должны были решать внутренние проблемы.

- Изменилось региональное отраслевое деление при реализации проектов. Так, до этого в Северной Африке основной отраслью, в которой осуществлялось сотрудничество, была отрасль высоких технологий, в том числе распространение ИКТ. В странах к югу от Сахары напротив, основной упор делался на развитие сельского хозяйства. По новому принципу, чёткое деление сорер влияния размывалось, Корея старалась организовывать проекты во всех странах по одинаковым направлениями, опираясь на собственный потенциал.

По оценке специалистов стратегия проявила большую результативность в Центральной и Западной Африке, там 72,7\% проектов были успешно завершены и притворены в жизнь, а вот в Северной Афррике напротив эфрфективными оказалось только 33,3\% проектов. Самыми успешными оказались образовательные проекты и проекты здравоохранения, как мы можем видеть в таблище 1, почти везде было 90-100\% достигнуто совпадений, хуже всего себя проявили правительственные проекты в сфере управления, они показали лишь 40\% работоспособность в Юго-Восточной Африке. Остальные группы проектов демонстрирую неоднозначную корреляцию, в одном регионе они были максимально эффрективны, а в другом особой результативности выявлено не было.

Таким образом, Республика Корея в рамках инициативы развития продвигает идеи и проекты, которые должны создать положительное впечатление о стране. Роль наставника и друга, который в приоритет выносит проекты, которые необходимы региону, а не те, которые принесут наибольшую прибыль. Так как в перспективе соответствующие необходимости проекты более окупаемы и имеют потенциал к развитию.

В 2013 г. президентом стала Пак Кынхе. Её политика в отношении Афррики может быть охарактеризована как борьба с присутствием Северной Кореей на континенте. После испытаний баллистических ракет с ядерной боеголовкой в декабре 2012 г. внешняя политика в отношении Северной Кореи была резко изменена. Администрация Пак Кынхе активно призывала другие страны изолировать Северную Корею, в этом стремлении её поддерживала 
ООН. Она встречалась с главами африканских государств, которые на протяжении долгих лет сотрудничали с Северной Кореей. Так во время визита президента Уганды Йовери Мусевени в Сеул, они обсуждали вопрос расширения коммерческих связей, сотрудничества в сфере безопасности и увеличения поддержки образования [7, с. 32]. Стоит отметить, что Уганда во всех этих областях продолжительное время сотрудничала с Северной Кореей. Пак Кынхе придавала большое значение увеличению объёмов гуманитарной помощи с целью заручиться поддержкой в вопросе изоляции Северной Кореи, а также для того, чтобы эти страны призвали Север отказаться от ядерного вооружения. В последствии это заметное увеличение объёмов гуманитарной поддержки, направляемой для осуществления этих целей, будет подвергнуто критике со стороны экспертов и будет названо чрезмерным и недальновидным.

В этот период в соответствии с политическим видением администрации Пак Кынхе, которое заключалось в создании "Счастливой глобальной деревни" (при активном участии Республики Корея в роли посредника), формируется новый подход к сотрудничеству и поддержке Африки. Продвигается политика публичной дипломатии в области языка и культуры. Корейский язык и культура в этой парадигме выполняют роль базиса и связующего элемента в процессе развёртывания "Счастливой глобальной деревни". Основная идея звучит следующим образом: "Продвижение счастья, а также достижение взаимопонимания через хангыль и корейскую культуру, что в последствии должно помочь участникам корейских программ повышения квалификации достичь экономических выгод и способствовать развитию собственных стран" [10, c. 35-37]. Однако из-за отсутствия индраструктуры во многих странах этого региона, языковые и образовательные программы в основном продвигались в Северной Африке и их количество несло весьма ограниченный характер.

Кроме продвижения публичной политики, при Пак Кынхе, творчески перерабатывается проект "Движения за новую деревню" для применения в Афррике. Усовершенствованная модель делала возможным передачу и внедрение опыта Кореи в преодолении бедности и отсталости для создания собственного процветающего государства. "Движение за новою деревню" - экономическая региональная политика, созданная по инициативе Пак Чонхи, которая продвигалась в 70-х гг. ХХ в. Впоследствии наравне с другими инновационными решениями она сыграла большую роль в экономическом развитии Республики Корея. Основная идея этой политики заключалась не только в развитии инфраструктуры, строительстве специальных сооружений, механизации сельскохозяйственных и производственных процессов, но и в качественной подготовке квалифицированных кадров, которые должны были стать лидерами и активными участниками этого движения. Модель "Движения за новую деревню" понравилась ряду африканских стран, на данный момент, с участием Республики Корея в качестве консультанта и донора, она реализуется в Эфиопии, Уганде, Кот-д'Ивуар, Бурунди и Конго [11].

После импичмента Пак Кынхе в мае 2017 г. кресло президента занял Мун Джэин. В отличии от своей предшественницы новый президент определил приоритетным сближение с Северной Кореей. В связи с чем он не расценивает Афррику как место конкурирования с Севером или в качестве своеобразного рычага давления. Администрация Мун Джэина переориентировала свою политику исключительно на экономическое развитие и коммерческое сотрудничество. Основные направления новой внешней политики в Африке заключаются в поддержке развитии человеческого капитала, с особым акцентом на молодёжь, продвижение технологического прогресса и поддержка предпринимателей. Для этих целей организуются различные форумы, например, молодёжный бизнес-форум Корея-Африка, где молодые предприниматели или просто молодые инициативные люди представляют готовые продукты или инициативные разработки, а также обмениваются опытом и знаниями.

В начале 2020 г. была представлена "Вторая региональная стратегия для развития Африки". При её создании были учтены проблемные моменты, которые проявились во время осуществления первой стратегии, также при разработке были включены новые Цели устойчивого развития, представленные в ООН в 2015 г. и "Повестка дня Африканского союза до 2063 г.". Новая стратегия придаёт особое значение гендерному равенству и поддержке моло- 
дёжи. При создании и реализации проектов делает упор на 4P (People, Peace, Prosperity, Planet) [8, c. 7].

При рассмотрении содержания Второй стратегии можно выделить 3 блока, которые определяют направление сотрудничества. Первые два - это гендерная политика и поддержка молодёжи - одинаково применимы ко всем регионам Африки. А вот третий блок региональной стратегии диверсифицирован для каждого района в зависимости от внутренних потребностей.

Гендерная политика, как часть Второй региональной стратегии, носит название Fill the GAP. Она соответствует пятой Цели устойчивого развития, заключается в обеспечение гендерного равенства, расширение прав и возможностей для женщин всех возрастов. В первую очередь рассматривается возможность полного включения женщин в состав рабочей силы, это должно помочь экономическому развитию региона. Кроме того, эконмическая независимость женщин способствует формированию безопасной среды, в которой женщина чувствует себя защищённой, увеличивается её участие как в экономической, так и в политической жизни страны. Что, в свою очередь, может поспособствовать демократизации и преодолению общей отсталости государства.

Программа по поддержке молодежи или Youth Build Program должна помочь в решении проблемы занятости молодёжи. Будет осуществляться поддержка молодых предпринимателей, а также в зависимости от регионального развития будут создаваться начальные и профессиональные образовательные программы для подготовки кадров, которые в первую очередь востребованы на рынке труда.

Региональная стратегия разделена по трём территориальным областям: Северная Африка, Центральная и Западная Африка, Юго-Восточная Африка. Ниже представлены основные пункты этой стратегии:

- В Северной Афррике вместе с поддержкой профессионального образования и цифровизации административных сервисов, направленных на увеличение товарооборота, выдвигаются проекты решения проблемы безработицы среди населения как превентивная мера против региональных конфликтов.

- В Центральной и Западной Адрике будет осуществляться поддержка инклюзивных образовательных программ для увеличения товарооборота, медицинская поддержка матери и ребёнка, поддержка отрасли сельского хозяйства, проекты по обеспечению питьевой водой. Для решения продолжающихся региональных конфликтов будет привлекаться Международная сеть по конфликтам и нестабильности ОСЭР (INCAF).

- В Юго-Восточной Африке также осуществляется поддержка профрессионального образования для увеличения будущего товарооборота, медицинская поддержка матери и ребёнка, помощь при реагировании на климатические изменения. Сотрудничество со странами Афрриканского рога посредством восточноафриканских организаций для решения внутрирегиональных проблем и конфликтов [8, с. 7-10].

При сравнении основного содержания Первой и Второй стратегии регионального развития можно отметить, что во втором варианте сильнее проявляется политическое видение действующего правительства. Во всех регионах планируется осуществлять поддержку молодёжи в области профессионального образования с целью наращивания экономического потенциала африканских стран и более эффективного сотрудничества, основанного на схожих принципах, в будущем. Также в отличие от прошлой стратегии придаётся большое значение поиску способов предотвращения и предупреждения региональных конфликтов, для этих целей планируется привлекать как внутренние ресурсы, так и международные организации. Так, благодаря стратегии развития формируется позитивный образ не только для Африки, но и для всей международной общественности.

\section{Задачи и ресурсы "мягкой силы"}

Рассматривая отношения Республики Корея и Афррики на протяжении всего периода дипломатических отношений, можно сказать, что, несмотря на часто звучащий экономический подтекст, основное значение так или иначе придаётся геополитике. Сотрудничество с африканскими странами решает сразу несколько задач, которые являются важными для неё в процессе пере- 
хода к "зрелой глобальной державе". Можно выделить следующие цели, которые она преследует, используя "мягкую силу":

- расширение рынков сбыта;

- повышение престижа бренда Республики Корея;

- международное сотрудничество в рамках проектов развития Адрикки;

- укрепление личной позиции на международной арене;

- влияние на отношения с Северной Кореей при участии третей сторо-

ны.

Говоря о ресурсах "мягкой силы", которые использует Республика Корея, можно рассмотреть разработки корейских исследователей. Они выделяют следующие ресурсы "мягкой силы", которые применяются во внешнеполитической стратегии:

1) успешный опыт быстрой модернизации и демократизации;

2) "Корейская волна" [5, с. 207].

После обретения независимости африканские страны столкнулись с проблемами, которые во многом схожи с теми, которые стояли на повестке дня Южной Кореи после освобождения от японской экспансии и Корейской войны. Этот схожий опыт и позитивный образ того, как Корея в короткие сроки смогла преодолеть трудности, определяют выбор в пользу первого ресурса, как основного для работы со странами Афррики. Большая часть африканских стран заинтересована в собственном развитии и преодоления трудностей, поэтому их привлекают чужие успешные модели, особенно если учесть, что Корея готова оказать поддержку для их осуществления. Так называемая "Корейская волна" здесь играет роль, скорее, вспомогательного ресурса, благодаря которому упрощается процесс адаптирования к программам и последующее взаимодействие.

Передача собственного успешного опыта в модернизации и демократизации особо подчёркивается в корейских стратегиях в африканском регионе, этот пункт был вторым в "Корейской инициативе развития Африки", Ли Мёнбак во время своих визитов на континент повторял эту мысль. Однако практика показала, что однообразные попытки внедрения аналогичных мер по преодолению бедности и отсталости не приносят никакого эфрфекта, а в некоторых случаях создают негативный. Пак Чондэ, посол Республики Корея в ЮАР, в своей книге, посвящённой переосмыслению развития Афррики, подчёркивает значение этического воспитания населения. Он говорит о том, что невозможно передать собственный опыт, внедрить новые технологии, если как на правительственном, так и на гражданском уровне будет сохраняться халатность, посредственность в работе и безразличие к всему, что происходит [4, с. 286]. В этом контексте публичная политика, продвигающая корейскую культуру посредством корейского языка, может оказать влияние на мышление молодого населения. Однако современный масштаб подобных программ недостаточен, чтобы проявился значительный эфрфект.

Ресурс "мягкой силы" Республики Корея, который представлен в виде так называемой "Корейской волны" или "Халлю" по сравнению с другими регионами в Адрике применяется не так широко. Однако он имеет важное значение. Кроме связующего звена для эффективного продвижения моделей развития и других проектов сотрудничества, "Корейская волна" через распространение корейской музыки и сериалов, которые стали особенно популярны в последнее время, формирует привлекательный образ не только с точки зрения культуры, но и быта. В итоге у многих реципиентов возникает желание посетить страну или как минимум приобрести товар, который с ней связан. K тому же хорошее впечатление на подсознательном уровне вырабатывает у нас доверие к товарам, произведённым в этой стране. В последние несколько лет заметно увеличился импорт корейской косметики, электроники и других предметов потребления в странах Африки, особенно этот рост заметен в Северной и Центральной части.

\section{Заключение}

Из года в год в Республике Корея увеличивается интерес к африканскому континенту. Меняются сферы интересов, а вместе с ними изменяются и инструменты, ресурсы и стратегии сотрудничества. Изначально политика в отношении Афррики носила весьма условный характер, её основной целью 
являлась конфронтация с КНДР, а также поиск союзников в этом противостоянии.

В начале 2000-х гг. эта тенденция несколько поменялась, начиная с этого периода афрриканский континент рассматривается как регион с неограниченным потенциалом роста. Тогда же Корея стремилась расширить свои рынки сбыта и диверсифицировать структуру импорта природных ресурсов, поэтому решает расширить экономическое сотрудничество. Кроме того, оказание гуманитарной помощи в целях развития и активное участие в международных организациях и проектах в перспективе должны повысить престиж бренда Республики Корея и увеличить её вес на международной арене.

Несмотря на то что основной курс политики, оформленный в конфронтации с Северной Кореей, перестал быть приоритетным, корейское правительство, сотрудничая со странами, которые находятся в дружественных отношениях с Севером, продолжает использовать регион как своего рода рычаг воздействия на северокорейское государство. Однако не всегда это воздействие имеет негативную подоплёку. Например, администрации Но Мухёна и Мун Джеина стремились к сближению и налаживанию отношений с КНДР, поэтому поддерживали позитивную коннотацию при построении стратегии, передавая через лидеров афрриканских стран свою готовность к диалогу.

Подводя итог, можно выделить следующие отличительные особенности использования "мягкой силы" Республики Корея в африканском регионе:

1) Избегание колониальных и әкономически оппортунистических позиций по отношению к Африке. Реализация дискурсивной стратегии "чуткого государства", которое может делиться опытом и перспективами развития. Признание Афррики субъектом, а не объектом для создания интерсубъективности.

2) Выбор целевых областей с точки зрения качественного подхода, а не количественного в противовес стратегии многоцелевого подхода, присущего китайскому или японскому стилю. То есть Корея не стремиться занять как можно больше отраслей, а выбрать несколько, в которых она конкурентоспособна и которые в перспективе принесут большую доходность.

3) Участие в проектах развития, использующих высокий потенциал $\mathrm{Pe}$ спублики Корея, а не просто участие в крупномасштабных проектах поддержки.

4) Творческое преобразование и применение "Движения за новую деревню" в условиях африканских стран в рамках передачи собственного опыта модернизации и демократизации.

5) Меры политического поощрения и поддержки для активного стимулирования входа частного бизнеса на рынок. Усиление местных предприятий, помощь при расширении их деловых возможностей.

6) Второстепенная вспомогательная роль "Корейской волны".

В целом внешнеполитическая стратегия Республики Корея схожа с международной практикой, она основана на общих концепциях и разработках, которые предлагают международные организации. Однако все эти концепции переработаны с опорой на собственный опыт, возможности и внутренний потенциал Кореи.

\section{Литература}

1. Братерский М. В., Скриба А. С. Концепция "мягкой силы" во внешнеполитической стратегии США // Вестник международных организаций. 2014. Т. 9. № 2. С. $130-144$.

2. Тшилидзи Марвала, Индустрия 4.0: взгляд из Африки // ЮНЕСКО, [Электронный pecypc]. URL: https://ru.unesco.org/courier/2019-2/industriya-40-vzglyad-izafriki (дата обращения: 01.12.2020 г.).

3. Africa // Ministry of Foreign Affairs, [Electronic resource]. URL: http://www.mofa. go.kr/ (дата обращения: 02.12.2020 г.).

4. Jong-Dae Park, Re-Inventing Africa's Development. London : Palgrave Macmillan. 2019. $449 \mathrm{p}$

5. Lee Geun. A theory of soft power and Korea`s soft power strategy // Korean Journal of Defence Analysis, 2009. Vol. 21, № 2, June. Pp. 205-218.

6. Nye Joseph S. Bound to lead: the changing nature of American power. Basic Books, 1990. 167 p. 
7. Seung-Woo Sim, Sung-Soo Kim, Economic Exchange between Korea and Africa, and the Plan of Peace and Diplomacy // The Journal of Peace Studies, 2019. Vol. 20, No. 4. Pp. 7-25.

8. KOICA 대아프리카지역협력전략. 성남 : 한국국제협력단, 2020. 139 쪽. [Peгиональная стратегия KOICA для развития Африки. Соннам : Хангук Кукчэхёмнёктан, 2020. 139 c.].

9. KOICA의 對아프리카 지역전략 "Hope With Africa" (2012-2015). 성남 :한국국 제협력단, 2012. 88 쪽. [Региональная стратегия KОICА для развития Африки "Норе With Africa" (2012-2015). Соннам : Хангук Кукчэхёмнёктан, 2012. 88 с.].

10. 변웅, 한국의 대(對)아프리카 외교 추진전략 // 정책연구과제. № 2, 2014. 21-49叒. [Пён УН, Корейская стратегия дипломатии в Африке. С. 21-49.]

11. 새마을운동 글로벌 확산 박차 [Стимуляция глобального распространения "Движения за новую деревню"] // Ministry of the Interior and Safety, [Electronic resource]. URL: https://www.mois.go.kr/ (дата обращения: 05.12.2020 г.).

12. 아프리카 개발을 위한 한국 이니셔티브. 서울: 외교통상부, 2006. 15쪽. [Koрейская инициатива по развитию Африки. Сеул : Вэгётхонсанбу, 2006. 15 с.].

\section{Транслитерация по ГОСТ 7.79-2000 система Б}

1. Braterskij M. V., Skriba A. S. Kontseptsiya "myagkoj sily" vo vneshnepoliticheskoj strategii CSHA // Vestnik mezhdunarodnykh organizatsij. 2014. T. 9. № 2. S. 130-144.

2. Tshilidzi Marvala, Industriya 4.0: vzglyad iz Afriki // YUNESKO, [EHlektronnyj resurs]. URL: https://ru.unesco.org/courier/2019-2/industriya-40-vzglyad-iz-afriki (data obrashheniya: $01.12 .2020 \mathrm{~g}$.).

3. Africa // Ministry of Foreign Affairs, [Electronic resource]. URL: http://www.mofa. go.kr/ (data obrashheniya: 02.12.2020 g.).

4. Jong-Dae Park, Re-Inventing África's Development. London : Palgrave Macmillan. 2019. $449 \mathrm{p}$.

5. Lee Geun. A theory of soft power and Korea`s soft power strategy // Korean Journal of Defence Analysis, 2009. Vol. 21, № 2, June. Pp. 205-218.

6. Nye Joseph S. Bound to lead: the changing nature of American power. Basic Books, 1990. $167 \mathrm{p}$.

7. Seung-Woo Sim, Sung-Soo Kim, Economic Exchange between Korea and Africa, and the Plan of Peace and Diplomacy // The Journal of Peace Studies, 2019. Vol. 20, No. 4. Pp. 7-25.

8. KOICA 대아프리카지역협력전략. 성남 : 한국국제협력단, 2020. 139 쪽. [Regional'naya strategiya KOICA dlya razvitiya Afriki. Sonnam : KHanguk Kukchehkhyomnyoktan, 2020. 139 s.].

9. KOICA의 비이아프리카 지역전략 "Hope With Africa" (2012-2015). 성남 :한국국 제협력 단, 2012. 88 쪽. [Regional'naya strategiya KOICA dlya razvitiya Afriki "Hope With Africa" (2012-2015). Sonnam : KHanguk Kukchehkhyomnyoktan, 2012. 88 s.].

10. 변웅, 한국의 대(對)아프리카 외교 추진전략 // 정책연구과제. №2, 2014. 21-49쪽. [Pyon Un, Korejskaya strategiya diplomatii v Afrike. S. 21-49.]

11. 새마을운동 글로벌 확산 박차 [Stimulyatsiya global'nogo rasprostraneniya "Dvizheniya za novuyu derevnyu"] // Ministry of the Interior and Safety, [Electronic resource]. URL: https://www.mois.go.kr/ (data obrashheniya: 05.12.2020 g.).

12. 아프리카 개발을 위한 한국 이니셔티브. 서울: 외교통상부, 2006. 15쪽. [Korejskaya initsiativa po razvitiyu Afriki. Seul : Vehgyotkhonsanbu, 2006. 15 s.]. 
Журавлева Н. С. Республика Корея в Африке: "Мягкая сила" как базовый инструмент политики.

В данной статье рассматривается процесс становления и развития отношений Республики Корея со странами Африки. Анализируются основные инструменты и ресурсы "мягкой силы", применяемые Республикой Корея для закрепления в регионе и наращивания своего влияния. В ходе этого анализа изучаются ключевые современные стратегии, разрабатываемые корейским правительством и исследователями. Предпринимается попытка выделить главные отличительные особенности южнокорейских стратегий "мягкой силы" на африканском континенте.

Ключевые слова: Республика Корея, Южная Корея, Африка, внешняя политика, "млгкая сила", публичная дипломатия

Zhuravleva N. S. The Republic of Korea in Africa: Soft Power as a Basic Tool of Foreign Policy.

This article examines the process of formation and development of relations between the Republic of Korea and African countries. The article analyzes the main tools and resources of Soft power used by the Republic of Korea to consolidate in the region and build up its influence. This analysis examines the key current strategies being developed by the Korean government and researchers. There is an attempt to highlight the main distinctive features of South Korean Soft power strategies on the African continent.

Key words: Republic of Korea, Africa, Foreign Policy, Soft power, Public diplomacy

Для цитирования: Журавлева Н. С. Республика Корея в Африке: "Мягкая сила" как базовый инструмент политики // Ойкумена. Регионоведческие исследования. 2021. № 3. C. 134-144. DOI: 10.24866/1998-6785/2021-3/134-144

For citation: Zhuravleva N. S. The Republic of Korea in Africa: Soft Power as a Basic Tool of Foreign Policy // Ojkumena. Regional researches. 2021. № 3. P. 134-144. DOI: 10.24866/1998$6785 / 2021-3 / 134-144$ 